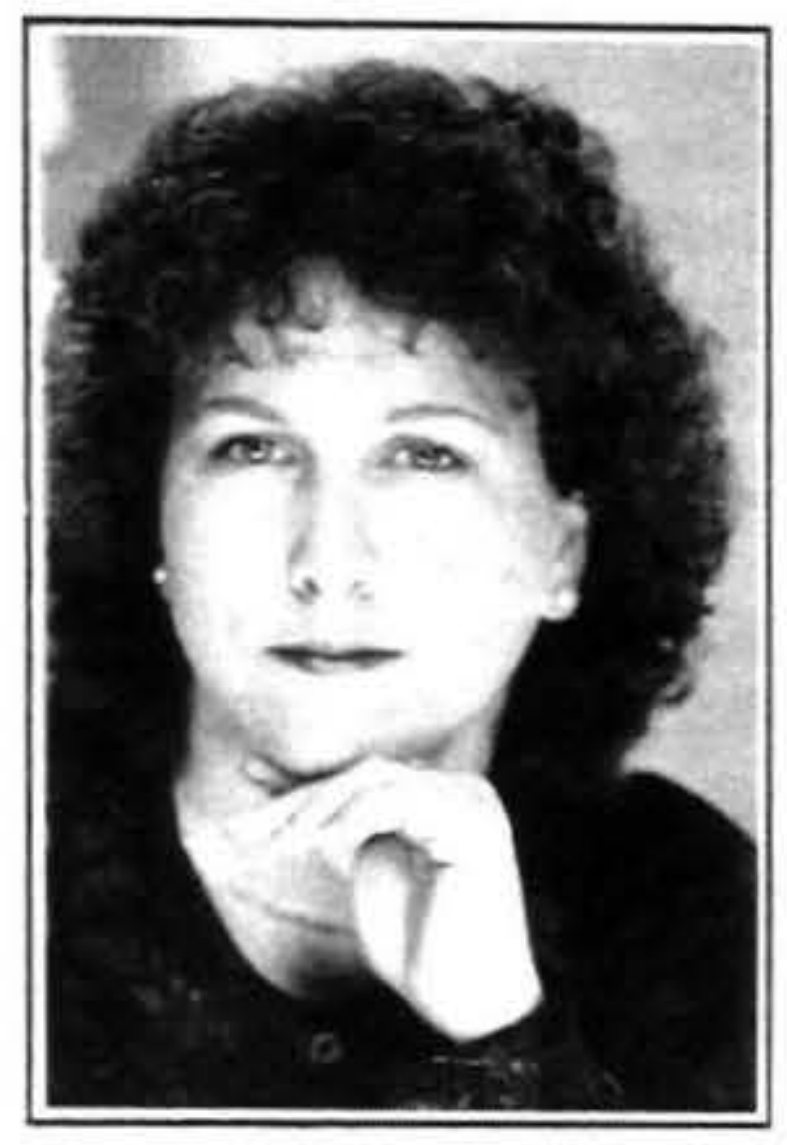

\title{
SHIFTING GEARS: THE TOLL OF SHIFTWORK IN NEW ZEALAND MANUFACTURING
}

\author{
Marie Wilson \\ University of Auckland
}

\begin{abstract}
Shiftwork has increased dramatically in recent years, mainly due to the expansion of service industries and extended hours of operation. Manufacturing, targeted for decline, is still a dominant shiftwork employer, particularly in a move to leverage physical plant and meet variable demand levels. This productivity comes at often dramatic human costs. A 12-year longitudinal study of New Zealand process manufacturers was undertaken to document shift patterns and establish their impact on organisational performance and employee well-being. This paper reports the results of questionnaire and interview data relating shiftwork and shift patterns to health and well-being. The historical domination of the eight-hour, reverse rotating shift is noted, and linked to increased sleep disorders, digestive problems, and use of prescription and non-prescription drugs. Disruption to family and social life were also reported. These adverse effects are heightened by lack of training and support and moderate to heavy utilisation of overtime. The author suggests shiftwork reforms to address some of these issues.
\end{abstract}

Shift. A period of continuous work during a working day, denoted by length (eg. an 8 hour shift) and/or by the time during any 24 hours in which it takes place, eg. day shift, aftemoon shift, night shift; also used to describe the group of workers involved eg. 'the day shift' etc. Shift systems include double day shift and three shift systems of various types; see also continental shift system, continuous three shift system, discontinuous three shift system, fixed shifts, rotating shift, twilight shift, graveyard or lobster shift, split shift, swing shift, relief shift. (Marsh, 1979, 275).

The 'standard' working day in New Zealand is one which starts between 7.30 and 8.30 am and which finishes roughly eight hours later. The majority of paid employees in New Zealand and in other developed nations work these sort of hours each day, week in and week out, year in and year out. Although most workers work about eight hours a day: "Many industrial establishments and some institutions ... remain open for work for substantially longer periods round the clock. In such cases workers are employed in 'shifts' of fixed numbers of hours" (Jones \& Morris, 1982, 252).

These workers are shiftworkers and they are employed on a wide range of different shift systems. Some $20-25 \%$ of those employed in manufacturing industries and an increasing proportion of those employed in the service sector are required to work on some form of shift system. The implications of this for the health and safety of the individuals concerned and for society as a whole are currently a topic of major concern. This is reflected both in the
Commission of the European Communities' current proposal for a 'Directive concerning certain aspects of the organisation of working time', and in the US Congress, Office of Technology Assessment report on Biological Rhythms: Implications for the Worker (1991). Within the United Kingdom this concern has also resulted in new and proposed regulations governing the work hours of those employed in a number of specific, and especially in potentially high hazard situations including air traffic controllers, junior hospital doctors, police and seafarers (Folkard, 1993).

Both the starting and finishing times of the shifts and the periods of rotation vary considerably depending upon the service, the industry or the employer involved. Shifts also vary as whether they are fixed (eg, permanent night shift) or rotating, and if rotating the speed of rotation (days elapsing before a different shift is worked) and whether the direction of rotation is clockwise or anti-clockwise. Shiftwork rosters may apply to individuals or groups and may be supported by training and/or access to food, light and medical or other resources to widely varying degrees.

There are three reasons commonly cited for the operation of shifts in a workplace:

(a) to extend the availability of essential community and emergency services, for example hospital, police, fire and ambulance services;

(b) to ensure continuity of production within industries where this is a necessity for the technical process 
involved, for example in steelworks, oil refineries and glassworks industries; and

(c) to make the fullest possible use of industrial plant for economic reasons, for example in the food processing, electrical engineering and car industries.

While the majority of New Zealand workers employed on shiftwork are not providing essential services, a substantial proportion are involved with operating a continuous process or plant. The cost effectiveness of these operations is high in financial terms. Of more pressing concern to workers, however, is the cost in human terms: health, safety and quality of life.

Costa (1990) puts the human costs of shiftwork under four headings: these are amplified in Jansen, Vos and De Haan (1990).

* Biological rhythms and performance.

Circadian rhythms are disturbed, most noticeably the sleep/wake cycle. Beyond sleeping and waking itself, performance varies considerably by the biological rhythms of the body, particularly with regard to speed and agility both physical and mental. Producing efficient and error-free performance is more difficult at some stages in the 24 hour cycle - more costly in terms of effort, and more risky in terms of accidents. This has gained particular attention through the retrospective analysis of industrial catastrophes such as Three Mile Island and Bhopal.

\section{* Medical.}

Objectively shiftworkers tend to have more gastrointestinal problems; subjectively, more discomfort; psychologically, more risk of anxiety, fatigue, depression, and irritability. Recently, a higher incidence of heart disease has been found in some shiftworkers (Knutsson 1989). Recent reviews (Agervold, 1976; Dunham, 1977) have documented a number of problems that occur with greater frequency for shift workers than for those on regular day schedules. Physical problems have included sleep disruption, appetite and digestive disturbances, elimination problems, upper gastrointestinal disorders, poor general medical health, and disrupted rhythmic functioning. The psychological effects of shift work are reflected in patterns of social and solitary activity, relationships with one's family and spouse, general psychological health, and job satisfaction. Finally, sociological analyses of problems related to shift work have highlighted the importance of the worker's surrounding social community (Dunham, 1977).

* Social.

Maintaining normal relationships both inside the family, and in wider contacts with normal society, is more difficult, with negative consequences for marital relations, parent/child relationships, further education, social friendships, and general community participa- tion. This is particularly true if the shiftwork involves weekend working, when many important community events occur, and most people are not working. This varies as a function of community support and may be ameliorated in communities where a high proportion of the workforce is employed on shifts or in 24-hour metropolitan societies; in either case a broader range of options is available in non-traditional time slots.

\section{* Financial.}

There are many direct financial penalties for trying to adapt to shiftwork. For example, BEST 3 suggests a wide range of adaptive steps that shiftworkers can take, including better sound insulation outside and inside the house, better transport, heavier curtains for light protection, air-conditioning, video-recorders, and even the possibility of moving house to a quieter area. These suggestions add up to major expenses for the committed but troubled shiftworker. The limitations on the work of spouses for families with younger children may also pose a financial disadvantage.

While a number of ILO-sponsored and BEST-documented initiatives have been undertaken internationally to chronicle existing patterns of shiftwork and document best practice, little research has probed New Zealand practice and directions. This research constructed 12 year archival case studies of six New Zealand process manufacturers and combined these with contemporary health surveys of 2306 of their employees and in-depth interviews with 42 , to profile the impact of shiftwork on the process manufacturing employee in New Zealand.

\section{Method}

Fourteen process manufacturing sites were identified in New Zealand and were approached to participate in a research project on shiftwork that involved historical analysis of company records, a series of management and employee interviews, and an optional employee survey. Ten agreed to participate, but four were eliminated for insufficient record-keeping to support the study objectives. The remaining six companies became the site of twelve year retrospective case studies utilising financial, operational and personnel records on a monthly basis, as well as detailed data gathering on shift patterns and support. Longitudinal multivariate analysis of archival data was combined with observational and interview based case studies to build comprehensive organisational profiles. In addition, employees were approached for interviews and, on a broader basis, to complete an augmented version of the General Health Questionnaire. Data from 790 returned questionnaires was subjected to non-parametric tests of difference, two way and multivariate ANOVA and qualitative assessment.

\section{Results}

The majority shiftwork pattern in the sample was the eight 
hour anticlockwise rotating shift, with frequent overtime and a low level of training and support. As summarised in table one below, most patterns could be seen as variations of two basic patterns. Pattern A covered approximately $72 \%$ of workers surveyed, $20 \%$ were covered by Pattern B, while the remainder observed a hybrid along the continuum between the two patterns.

\section{Table 1. Reported current shift patterns}

\begin{tabular}{lll}
\hline Shift Characteristic & Pattern A & Pattern B \\
\hline Hours in length & 8 & $10-12$ \\
Direction of rotation & Anticlockwise & Oscillating \\
Use of overtime & Frequent & Rare \\
Days off per week & 2 & $3-4$ \\
Training support & Nil & $3-5$ days \\
$\begin{array}{l}\text { Environmental support } \\
\text { (meals, lighting, etc) }\end{array}$ & Nil to low & moderate \\
Unit of rotation & Individual & Group \\
\hline
\end{tabular}

Across the sample, shiftworkers demonstrated significantly more health, social and related problems $(p<.05$, non-parametric assessment). As demonstrated partially in table two, the effect was most pronounced for sleep disruption, overall health status and family problems. Shiftworkers differed significantly from non-shiftworkers on five of the 32 measured health variables. Shiftworkers also reported significantly more disruption to family life (six times the level) and social life (three times the level). These differences were exacerbated in situations of frequent overtime, and moderated under low overtime, high support and twelve hour shift configurations.

In addition, shiftworker records revealed higher divorce rates (by $24 \%$ ), increased industrial accident rates (by
$320 \%$ ), and raised levels of absence due to illness (up $230 \%$ ). Shiftworkers discussed profound difficulties in sleeping and in maintaining a family life, and reported feeling 'trapped in a treacle pit', where the money was good but the consequences were devastating. In one site where shiftworkers' annual pay, including overtime and other premiums, occasionally surpassed that of the General Manager, all transfers from shiftwork were effected for medical reasons, and $100 \%$ of workers thus transferred died within 18 months of the transfer.

\section{Discussion}

The focus of this portion of the analysis was on documenting the human cost of shiftwork in the process industries, in general terms. While a dollar value may be assigned to absenteeism and injury (estimated conservatively at NZ\$4.3 million across this sample), the compromised health status of these individuals and the social costs are more difficult to estimate. Clearly the impact is greater in these areas, but the cost is infinitely more insidious and long term. Given the moderating effects of some simple changes to the shift system, changes to working shifts should be considered from both a business case and national policy perspective.

Generally, production and service requirements and social considerations interact withr working time options, in particular those involving night and shiftwork. Changes in working time schemes are thus usually a result of compromises that respond to the sometimes conflicting interests of employers and workers (Kogi 1985, Corlett et al, 1988, Thurman 1990). Often the views of employers and workers are far apart (Bosch 1990, ILO 1990, Kogi 1991). Trade unions may insist that weekend and night work should be avoided, that participation in inconvenient schedules should be voluntary, and that economic justifications alone should never be a sufficient reason to introduce shiftwork that could be harmful to the health of workers or

Table 2. Reported health symptoms (summarised)

\begin{tabular}{lll}
\hline Symptom & $\begin{array}{l}\text { Shiftworkers } \\
\text { (\% reporting) }\end{array}$ & Non-shiftworkers (\%) \\
\hline Disrupted sleep & 82.3 & 17.6 \\
Headaches & 75.4 & 12.1 \\
Difficulty falling asleep & 73.1 & 6.9 \\
Difficulty waking & 72.9 & 14.1 \\
Indigestion & 72.5 & 18.7 \\
Exhaustion & 68.2 & 5.1 \\
Difficult sleep & 66.9 & 19.3 \\
Moderate to high caffeine & & \\
$\quad$ consumption & 62.1 & 48.5 \\
Bowel difficulties & 41.5 & 12.2 \\
Use of prescription sleeping & & \\
pills (eg, Halcyon) & 36.2 & 2.1 \\
Moderate to high alcohol & & \\
$\quad$ consumption & 18.1 & 32.6 \\
Depression & 9.4 & 0.6 \\
\hline
\end{tabular}


disruptive to their family and social life. Employers maintain that, while certain workers may have difficulty in adapting to night work or to rotating shifts, there are no general harmful effects; and that night and shiftwork have positive effects on employment creation, production, economic growth, standard of living, and daytime leisure. Thus many reports show that when shiftwork schedules are introduced or revised a number of options are compared until a workable pattern is found. Work schedules are quite often proposed to extend operating hours during weekends or night hours, and workers tend to accept these in return for shorter hours. While a high degree of experimentation with shift patterns has been pursued internationally, New Zealand process manufacturers have demonstrated little variation from historical and often contra-indicated patterns. Given the human cost of such procedures, a re-evaluation appears overdue.

\section{Conclusion}

This sector of the New Zealand economy appears to still be utilising shift patterns that have been criticised for several decades as resulting in excessive physical strain and loss of attention and ability. The existing patterns are further compromised by extensive use of overtime and minimal or non-existent training and support. The result of such practices is expensive to the firm in terms of lost productivity, and expensive for the employee in terms of quality of life.

Improvements in employee health and well-being, as well as organisational performance, may be linked to longer shift length (with reduced opportunity for overtime), clockwise rotation, longer consolidated periods of non-work time (particularly after night shift), faster rotation and increased training on coping strategies for shiftworkers and their families. As a number of firms undergo workplace reform, an evaluation of the shift system is a fruitful area for thoughtful reconsideration of existing practice.

\section{Future research}

Process manufacturing was selected for this research because there is an in-built requirement for shiftwork, that is, shiftwork is not a matter of economic choice in the process manufacturing scenario; 24 hour operation is a minimum requirement. Manufacturing also affords a tangible product in terms of organisational performance, a plethora of international benchmarks, and high variability in health and accident rates.

While these characteristics are methodologically satisfying, the growth area for shiftwork research is in services, particularly in the differentiation of essential and nonessential services, and in the extension of hours for an often younger, lower paid workforce. The manufacturing arena is also limiting in another sense; its workers are generally middle-aged males. This group is a shrinking percentage of the general workforce and an even more rapidly shrinking proportion of the service and shiftwork labour force. While nurses vie with airline pilots for the status of the population with the most studied circadian rhythms, little has been done to integrate a broader range of service workers or to investigate and/or integrate the social and broader health impact of shiftwork.

The integration requires several steps. This research has been largely associative in linking shift patterns to health patterns; the next step is to undertake interventions that test the impact of each of the positively associated factors, eg, greater training and support, for its relative contribution to both individual and organisational effectiveness. Beyond that, a framework to guide practitioners in the construction of appropriate patterns for their context would be invaluable.

\section{References}

Agervold, A. 1976. Shiftwork: a critical review. Scandinavian Journal of Psychology, 17: 181-188.

Bosch, G. 1990 , From 40 to 35 h: reduction and flexibilization of the working week in the Federal Republic of Germany. International Labour Review, 129: 611-627.

Corlett, E.N., Quinnec, Y. and Paoli, P. 1988. Adapting Shiftwork Arrangements European Foundation for the Improvement of Living and Working Conditions, Dublin.

Costa, G. 1990. Compensative measures for shiftwork in Italy. European Foundation, Dublin.

Dunham, R. B. 1977. Shiftwork: A review and theoretical analysis. Academy of Management Review, 2: 624634.

Folkard, S. 1993. Night and shiftwork (editorial) Ergonomics 36 (1-3): 2-5.

International Labour Office, 1990. Conditions of Work Digest, Vol 9 (2) on the Hours we Work: New Work Schedules in Policy and Practice International Labour Office, Geneva.

Jansen, B., Vos, W.G.M. and De Haan, E.G. 1990. Compensation for shiftwork. European Foundation, Dublin.

Jones, J. and Morris, M. 1982. A-Z of Trade Unionism and Industrial Relations, : 252-260.

Knutsson, A. 1989. Shiftwork and coronary heart disease. Scandinavian Journal of Social Medicine, Suppl 44: 1-14.

Kogi, K. 1985. Introduction to the Problems of shiftwork. 
In S. Folkard and T.H. Monk (Eds) Hours of Work: Temporal Factors in Work Scheduling Wiley, Chichester: 165-184.

Kogi, K. 1991. Job content and working time: the scope for joint change. Ergonomics, 34: 757-773.

Marsh, A. 1979. Concise Encyclopedia of Industrial Relations. Industrial and Labor Relations Press, Cornell. 275-278.

Thurman, J. E. 1990. Working time. In R. Blanpain (ed.) Comparative labour law and industrial relations in industrialised market economies Kluwer, Deventer. 133-166.

Wedderburn, A. 1991. Guidelinesfor Shiftworkers, Bulletin of European Shiftwork Topics, Number 3. European Foundation for the Improvement of Living and Working Conditions, Dublin.

\section{Author}

Marie Wilson is Associate Dean of the Graduate School of Business at the University of Auckland, Private Bag 92019. Auckland. This research was supported by a grant from the Foundation for Research, Science and Technology. 